\title{
Assessment of Awareness and Knowledge About Rickets in Primary Health Care Centers in Saudi Arabia Based on Health Belief Model and Social Cognitive Theory
}

\author{
Alaa Alahmadi ${ }^{1,2}$, Hind Aljaloud ${ }^{1,2}$, Amen Bawazir ${ }^{1,2}$, Hoda Jradi ${ }^{1,2}$, Renad Alhaidari ${ }^{3}$ \& Eyad Alofi ${ }^{3}$ \\ ${ }^{1}$ King Abdullah International Medical Research Center, Ministry of National Guard Health Affairs, Riyadh, Saudi \\ Arabia \\ ${ }^{2}$ King Saud Bin Abdulaziz University for Health Sciences, Ministry of National Guard Health Affairs, Riyadh, \\ Saudi Arabia \\ ${ }^{3}$ Taibah University, Ministry of Education, Medina, Saudi Arabia \\ Correspondence: Alaa Alahmadi, MBBS, MPH, King Abdullah International Medical Research Center, Ministry \\ of National Guard Health Affairs, Riyadh, Saudi Arabia.
}

Received: July 8, 2020 Accepted: September 1, 2020 Online Published: September 10, 2020

doi:10.5539/gjhs.v12n11p65 URL: https://doi.org/10.5539/gjhs.v12n11p65

\begin{abstract}
Background: Rickets is considered a significant health issue affecting children especially infants and toddlers. Despite the development affordable and accessible of a health care system in Saudi Arabia, Saudi children had a high prevalence of rickets. This study aims to assess knowledge and awareness of mothers about rickets after short interventional program based on the health belief model and social cognitive theory.

Methods: A Quasi-experimental design pre-posttest type was carried out by using self-administered questionnaire. A sample size of 180 mothers who attended the well-baby clinic in primary health care centers in Riyadh and Medina Region were consented and then enrolled in the study. The questionnaire focused on 7 domains; demographic information and the other 6 domains based on health believe model and social cognitive theory.

Results: The mean scores of knowledge, self-efficacy, and health belief model constructs (susceptibility, severity, benefits) significantly increased. The mean score and the percentages of knowledge and health belief model constructs show changes between pretest and post test result with statistical significant $(27.9 \%$ in knowledge and self-efficacy, $34.9 \%$ in perceived susceptibility, $54.5 \%$ in perceived severity, $25.9 \%$ in perceived benefits, $11.7 \%$ in perceived barriers and $5.4 \%$ in cues to action) all were with a p-value of less than 0.05 .
\end{abstract}

Conclusion: Educational intervention based on social cognitive theory and health belief model were effective in improving knowledge, awareness and practice related to preventive behaviors of rickets.

Keywords: rickets, believe, model, social, cognitive, Saudi

\section{Introduction}

Rickets considers a major public health issue around the world. Rickets is disorders characterized by bone demineralization before growth plate to be caused. It is due to vitamin D deficiency (Wheeler, Dickson, Houghton, Ward, \& Taylor, 2015). Vitamin D has a different physiological function in many systems in the human body. Vitamin D is one of the fat-soluble vitamins that play a significant physiological function in musculoskeletal and immune systems in the human body (Misra, Pacaud, Petryk, Collett-Solberg, \& Kappy, 2008; Walker \& Modlin, 2009). Rickets targets children of different age group usually presented before 18 months while hypocalcaemia appear after two years as a result of weaning (Dijkstra, Arpaci, Huijsman, Boot, \& van den Akker, 2005). It has a significant impact on health that affects patient quality of life and causes high economic burden especially if it persists until adulthood (Munns et al., 2016). Rickets diagnosed by history, clinical examinations and laboratory test. A radiograph is one of the tools used to confirm the diagnosis of this illness (Fida, 2003).

Globally, Rickets prevalence is increasing and many children were affected by this illness. It mostly affects infant and the prevalence among them vary from $2.7 \%$ and $45 \%$ (Almeida et al., 2018). According to a studies conducted in Canada and in New Zealand the incidence rates of rickets among children was 2.9 and 10.5 per 100000 respectively (Ward, Gaboury, Ladhani, \& Zlotkin, 2007; Wheeler et al., 2015). In Brazil, the prevalence of children 
with Rickets between the ages of 8 to 24 months was $6 \%$. On the other hand, the prevalence of vitamin D insufficiency was $30 \%$ in studies done Brazil and Pennsylvania was $30 \%$ and $16 \%$ respectively (Almeida et al., 2018; Michel et al., 2015).

Although rickets is considered as a preventable disease, the prevalence of rickets between the Middle East and North Africa (MENA) is rising. The prevalence of rickets among children in MENA regions was ranging from $30 \%$ to $90 \%$ (Bassil, Rahme, Hoteit, \& Fuleihan, 2013). Among Arab countries the neonatal level of vitamin D was low and accounted for about $88 \%$. Neonatal hypovitaminosis was a result of maternal vitamin D inadequacy which had a prevalence of $85 \%$ (Fouda et al., 2017).

Regarding Saudi Arabia, a study conducted among Saudi children in different regions found that the prevalence of rickets among children was $15.3 \%$, the diagnosis was done at age less than five years, and only $35.9 \%$ of the Saudi population aware of the illness (Almezani, Alshlaqy, Alsiraa, Alenazy, \& Ghamdi, 2018). Another study found the $80 \%$ parents were conscious of vitamin D sources, and $50 \%$ knew the importance of vitamin $\mathrm{D}$ on human health and physiology (Alshamsan \& Bin-Abbas, 2016). Other studies found that vitamin D deficiency raises the chance of bone fracture among Saudi children of both genders, and Saudi children with dark skin had lower vitamin D concentration (Al-Daghri et al., 2016). In addition, prolonged breastfeeding without supplementation of vitamin D and decrease dietary intake of calcium predisposed to Rickets (Bassil et al., 2013; Dijkstra et al., 2005).

A study done in Jeddah on children from age 3-36 months reported the prevalence of rickets of $60 \%$ (Al-Atawi, Al-Alwan, Al-Mutair, Tamim, \& Al-Jurayyan, 2009; Fida, 2003). Additionally, another study done in Riyadh among children between 14 months and ten years found that $48 \%$ of children had a hypocalcaemic seizure as a complication of Rickets (Al-Atawi et al., 2009). In Medina, a prospective hospital-based study found that $63 \%$ of children with a mean age of 17 months were diagnosed with active rickets, and $37 \%$ of children with a mean age of 23.9 months had healed rickets. In addition, the study found that $8.1 \%$ of infants had convulsion due to rickets, $57.4 \%$ had bow leg, $24.3 \%$ had delayed dentition, $27.9 \%$ had delayed standing, $6.6 \%$ had craniotabes, and $80.9 \%$ had frontal bossing (Elidrissy et al., 2012).

It is of great need to focus on vitamin D deficiency among Saudi children due to the modernization of lifestyle and change of dietary habits in Saudi community, such as change in the type of residence, nature of physical activity \&insufficient exposure to the sun with emersion of modern technologies.

Mother plays an essential role in child health control not only during infancy and childhood but also during pregnancy in the embryo stage. Maternal health and vitamin D level during pregnancy have an impact on the fetus level of vitamin D additionally; children are highly vulnerable to rickets because of their need to vitamin D during growth. There are many factors that make rickets one of the high priority issues in public health. Despite the presence of guidelines for rickets still not enough to rescue children as vitamin D plays a vital role as safeguarding from a different pathological issue.

An effective preventive program about rickets should be directed to health care provider, mothers, and child. Preventive programs should target mothers of children with age less than 3 years to increase their awareness and knowledge about rickets, and to understand the physiological changes and nutritional need during each stage of child growth. The program also aims at focusing on high-risk groups as those with chronic illnesses, dark skin pigmentation, who have limited exposure to sun, and infants who exclusively breastfeed.

As the Cognitive behavior theory and health belief model are considered as the most effective models in health promotion and preventive medicine, this study aimed to assess knowledge and awareness of mothers about rickets after short interventional program based on health belief model and social cognitive theory.

\section{Material and Methods}

One-shot interventional quasi-experimental design/ pre-posttest type was conducted in March 2019. The study was done at the pediatrics and well-baby clinic in primary health care centers in Riyadh and Medina cities; Kingdom of Saudi Arabia. Using simple random sampling methodology, four primary health care centered were selected. From each center, 45 mothers were contacted and asked to participate in the study. However, the intervention phase was done for once and only post-test was used to measure the outcome of the intervention. No follow-up was used for long period as not of our aim to include long-term follo-up due to some logistics constrains. The inclusion criteria were: a) Being a Saudi child; b) parents of children aged 3 years old or less; c) living in Riyadh or Medina. The exclusion criteria were: a) immunocompromised children; b) Children with congenital anomalies; c) Being non-Saudi; d) Living outside Riyadh or Medina. 


\subsection{Study Instrument}

The self-administered questionnaire used focused on 7 domains; demographic information and the other 6 domains based on health belief model and social cognitive theory. Demographic information includes; age, gender, family income, level of education about mother and father, mother and father job, number of children and whether they had a child with rickets or not.

The other 6 domains had questions on a Likert scale type that ranged from strongly agree to strongly disagree with a score from 1-5. It included 20 items on personal factors, cognitive factors (knowledge and self-efficacy); 7 items on perceived susceptibility, 11 items on perceived severity, 6 items on perceived benefits, 8 items on perceived barriers, 2 items on cues to action.

Content validity was done by distribution of questionnaire to 5 experts. Face validity of the questionnaire was done on 30 mothers with similar inclusion characteristics, and all questionnaire questions were clear, understandable and measured what it is intended to measure. Predictive validity was done through pilot test and the participants in pilot test were not included in the health promotion program when fully implemented. Internal consistency of the instrument was good and overall Cronbach's $\alpha=0.85$. Cronbach's $\alpha$ was 0.86 for personal factors/ cognitive factors (knowledge and self-efficacy), 0.82 for perceived susceptibility, 0.81 for perceived severity, 0.917 for perceived benefits, 0.83 for perceived barriers and 0.80 for cues to action.

Test-retest reliability was done, and the assessment tool gave consistent result by redistribution of the same test to the same group for the second time after ten days, indicating that the questionnaire has achieved a stable reliability (kappa was $0.8876 \&$ agreement of $92.56 \%$ ).

\subsection{Implementation of Intervention:}

The intervention phase started by explanation of the intervention purpose, objectives and assurance of participants about the confidentiality. Verbal and written consents were obtained from all participants before sharing in the study.

Pre-test was distributed to participants, and education session for 20 minutes that included power point presentation, model showing rickets sign, brochure and question answer discussion that explain rickets definition, causes, signs and symptoms, complications, diagnosis, prevention and management was done. Later, a mother of a rickety child was invited as a model to talk about her experience in 10 minutes with help of an expert as physician. After that, the post- test was distributed to participants to assess result of intervention.

\subsection{Data Analysis}

Data were checked for completeness and consistency, and the SPSS software- version 22 was used for data analysis. Quanitative data were expressed as numbers, percentages, Mean and Standard deviation (Mean $\pm \mathrm{SD}$ ) and Wilcoxon test was used to assess the relationships between the pre and post test result. The statistical significance was considered with a $\mathrm{p}$-value of $<0.05$.

\section{Results}

(Table 1) shows that among the participant mothers $36.7 \%$ had children with an age ranging from 6-12 months, and $33.3 \%$ had children with an age that ranged from $13-24$ months. Of their children, $53.3 \%$ were males and $46.7 \%$ were females.

Table 1. Distribution of children according to their characteristics (N.: 180).

\begin{tabular}{cll}
\hline Variable & No. (\%) \\
\hline Age & & \\
- & Less than 6 months & $18(10)$ \\
- & $6-12$ months & $66(36.7)$ \\
- & $13-24$ months & $60(33.3)$ \\
- & $25-36$ months & $36(20)$ \\
\hline Gender & & \\
- & Male & $96(53.3)$ \\
- & Female & $84(46.7)$ \\
\hline
\end{tabular}


Half of the participant mothers had university education or higher and $68.9 \%$ were unemployed. As for fathers, $30 \%$ had university education or higher, and all of them were employed. The mean number of children was $(3.73 \pm$ 1.61). Of the participant mothers, $53.5 \%$ had a child with rickets, and the most of them was the second or third child. (Table 2).

Table 2. Distribution of children' parents according to their characteristics (No.: 180)

\begin{tabular}{|c|c|}
\hline Variable & No. $(\%)$ \\
\hline \multicolumn{2}{|l|}{ Mother education } \\
\hline - Uneducated & $22(12.2)$ \\
\hline - $\quad$ basic education & $28(15.6)$ \\
\hline - $\quad$ secondary education & $40(22.2)$ \\
\hline - $\quad$ university and higher & $90(50)$ \\
\hline \multicolumn{2}{|l|}{ Mother employment } \\
\hline - employed & $56(31.1)$ \\
\hline - $\quad$ un-employed & $124(68.9)$ \\
\hline \multicolumn{2}{|l|}{ Mother's job (No.: 56) } \\
\hline - $\quad$ nurse & $6(10.7)$ \\
\hline - teacher & $38 \quad 67.9)$ \\
\hline - $\quad$ accountant & $6(10.7)$ \\
\hline - $\quad$ receptionist & $6(10.7)$ \\
\hline \multicolumn{2}{|l|}{ Father education } \\
\hline - uneducated & $6(3.3)$ \\
\hline - $\quad$ basic education & $42(23.3)$ \\
\hline - $\quad$ secondary education & $78(43.3)$ \\
\hline - $\quad$ university and higher & $54(30)$ \\
\hline \multicolumn{2}{|l|}{ Father employment } \\
\hline - $\quad$ employed & $180(100)$ \\
\hline - $\quad$ un-employed & $0(0.00$ \\
\hline No of children (Mean \pm SD) & $3.73 \pm 1.61$ \\
\hline \multicolumn{2}{|l|}{ Having a child with rickets } \\
\hline - $\quad$ Yes & $96(53.3)$ \\
\hline - $\quad$ No & $84(46.7)$ \\
\hline Rank of the rickets child (Mean \pm SD) & $2.72 \pm 1.26$ \\
\hline
\end{tabular}

(Figure 1) The changes of the mean score were increased from pretest to posttest for knowledge domain, susceptibility, severity, perceived benefits and cues to action (76.52 \pm 7.56 vs. $76.82 \pm 7.11,18.75 \pm 5.05$ vs. $25.31 \pm 4.45,25.28 \pm 8.8$ vs. $39.06 \pm 6.17,13.9 \pm 5.26$ vs. $21.07 \pm 3.89,7.84 \pm 1.24$ vs. $8.26 \pm 1.47$; respectively). On the other hand, the mean score of barriers decreased form $32.31 \pm 4.2$ pretest to $28.45 \pm 4.8$ posttest. Moreover, an improvement was found in the mean score of all the SCT \& HBM constructs post-test compared to pre-test ( $\mathrm{p}=<$ 0.05 ), as seen in Table 3. 
Table 3. Comparison between the mean scores of knowledge, susceptibility, severity, benefits, barriers, and cues to action domains pre and post- test

\begin{tabular}{|c|c|c|c|c|}
\hline \multirow[t]{2}{*}{ Domain scores } & \multicolumn{2}{|c|}{$\begin{array}{l}\text { Mean scores of SCT \& HBM constructs } \\
(\text { mean } \pm \text { SD })\end{array}$} & \multirow[t]{2}{*}{ Wilcoxon Test } & \multirow[t]{2}{*}{ p-value } \\
\hline & Pre-test & Post-test & & \\
\hline Knowledge & $76.52 \pm 7.56$ & $76.82 \pm 7.11$ & 3.06 & 0.002 \\
\hline Susceptibility & $18.75 \pm 5.05$ & $25.31 \pm 4.45$ & 11.3 & $<0.001$ \\
\hline Severity & $25.28 \pm 8.8$ & $39.06 \pm 6.17$ & 11.57 & $<0.001$ \\
\hline Benefits & $13.9 \pm 5.26$ & $21.07 \pm 3.89$ & 11.21 & $<0.001$ \\
\hline Barriers & $32.31 \pm 4.2$ & $28.45 \pm 4.8$ & 6.55 & $<0.001$ \\
\hline Cues to action & $7.84 \pm 1.24$ & $8.26 \pm 1.47$ & 2.92 & 0.003 \\
\hline
\end{tabular}

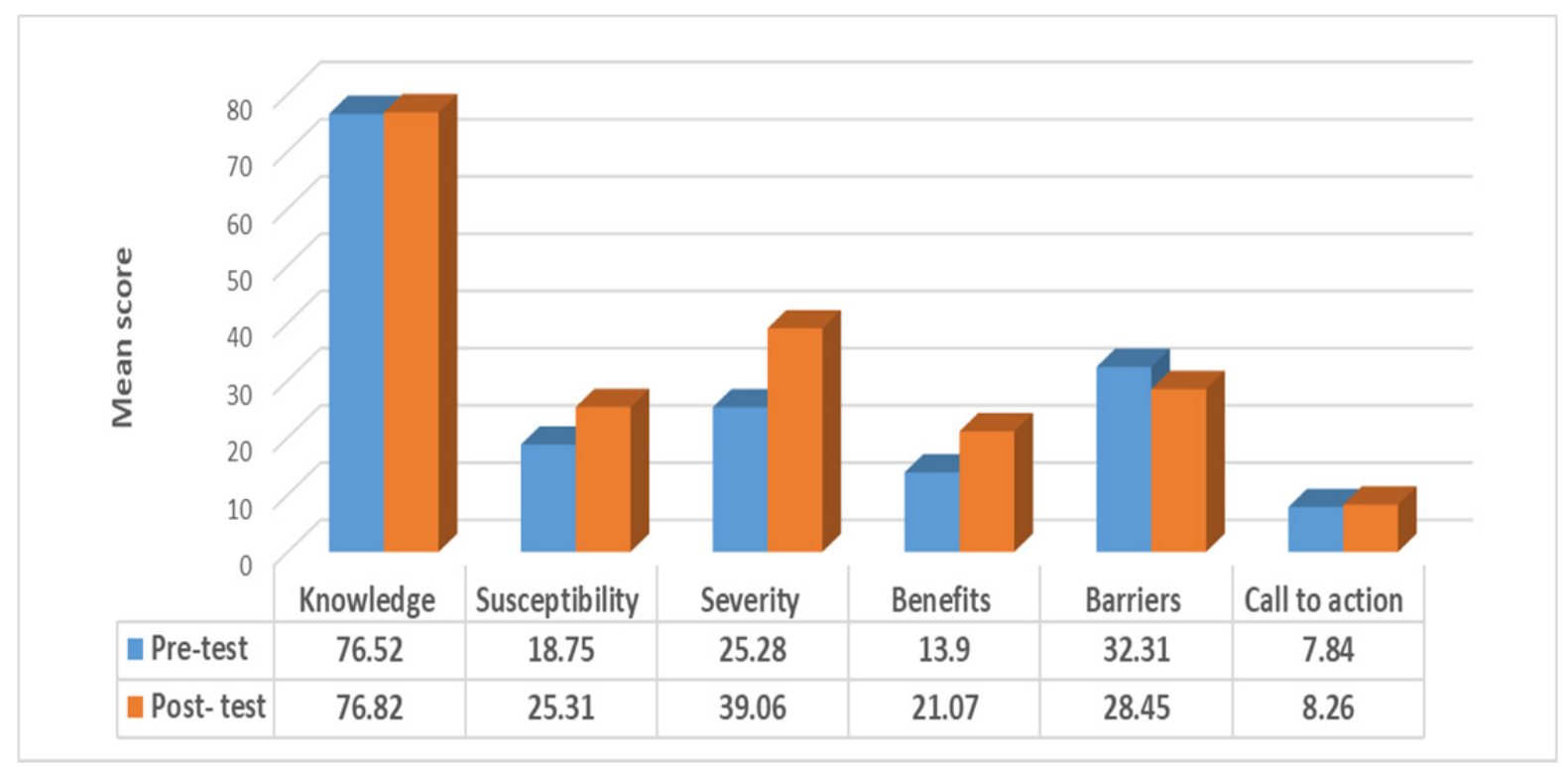

Figure 1. Mean scores of SCT \& HBM constructs before and after the intervention.

After implementation of the interventional phase, the severity domain had the highest percentage of improvement followed by the susceptibility, knowledge, benefits, barriers, and cues for actions domains, however differences between these domains were statistically significance (Figure 2). 


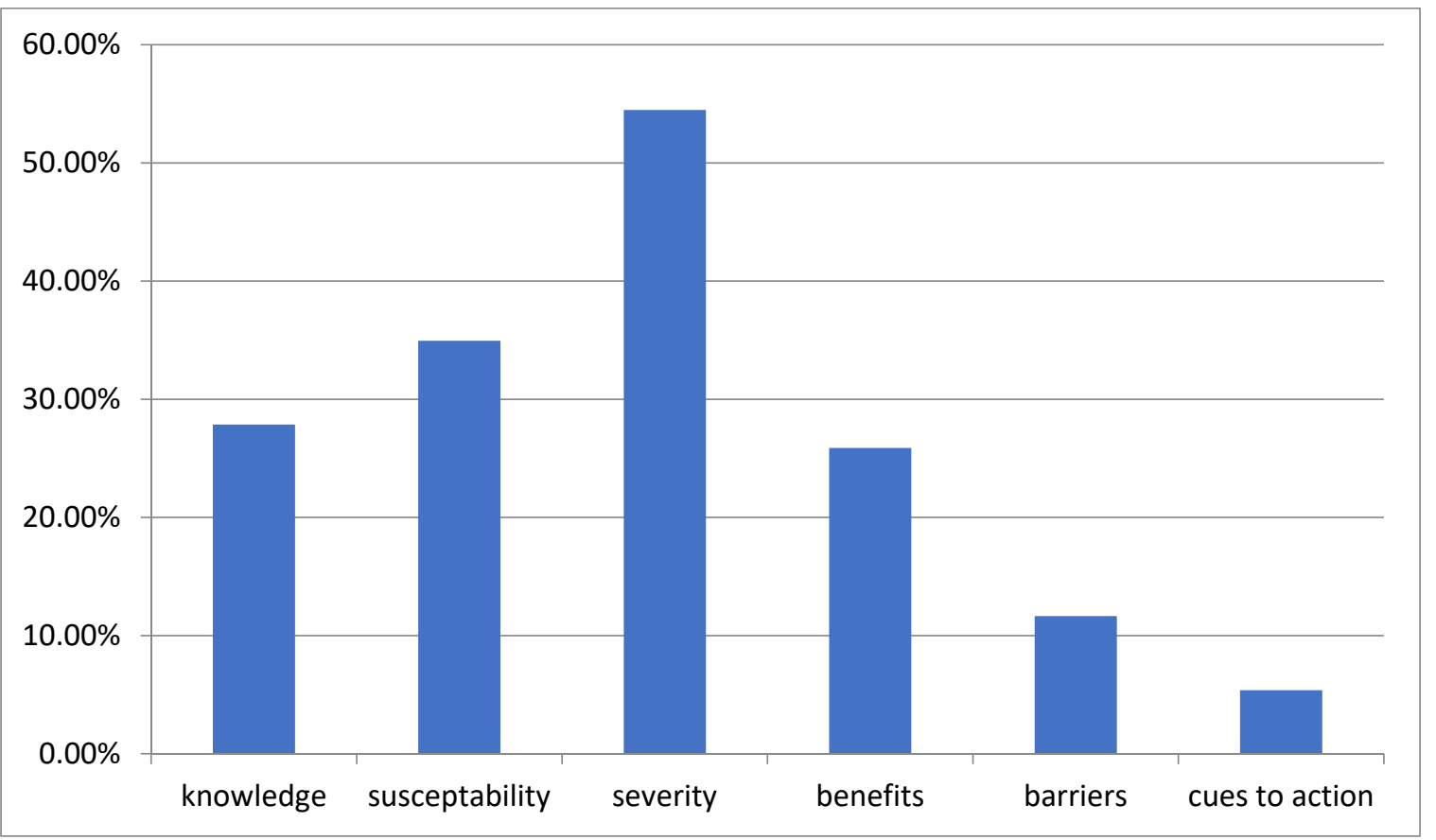

Figure 2. The percentages of improvement in social cognitive theory and health believe model constructs after the intervention (No.:180)

\section{Discussion}

In the present study, nearly half of the parents in the study had children with rickets (53.3\%). This result was in correspondence with the study conducted by Fouda et al. that showed that the prevalence of rickets is high among Saudi children in different regions of Saudi Arabia and found that the prevalence of diagnosed children with rickets was $15.3 \%$, and most of them were diagnosed at age less than five years (Fouda et al., 2017). Another study in Jeddah done on children from age 3 - 36 months reported a prevalence of rickets of 60\% (Fida, 2003).

This study demonstrated that there were significant differences between the mean scores of knowledge before and after the intervention. There was significant improvement in self-efficacy, which is one of the important factors that influence healthy behaviors and increased mean score of self-efficacy indicating increased chance in adopting the new behaviors. In addition, there were significant increase in the mean score of perceived benefits and significant decrease in the mean scores of perceived barriers. These figures are in agreement with the Jeihooni et al., study which reported a decrease in the mean score of perceived barriers after intervention of vitamin D deficiency prevention program among women in Iran (Jeihooni, Hidarnia, Kaveh, Hajizadeh, \& Askari, 2015).

It was reported that the increasing benefits and decreasing perceived barriers were predictive factors in adopting health behaviors (Khorsandi, Shamsi, \& Jahani, 2011). Providing educational intervention program were found to have a power in improving mother's knowledge and practices regarding rickets by decreasing barriers for good and healthy behaviors (Khorsandi et al., 2011).

The present study showed a significant increase in the perceived susceptibility after the intervention, which indicated an increased awareness of mothers about the importance of vitamin D supplementation during pregnancy to decrease susceptibility of rickets in early life of infants. This result is consistent with the findings of Khorsandi et al., study that reported a significant increase in knowledge and all HBM constructs after implementation of intervention among pregnant mothers (Khorsandi et al., 2011).

In this study, almost $54.4 \%$ of mothers acknowledge the severity of rickets after the intervention; they will expose their children to sunlight as they think it is an important source of vitamin D.

The current study demonstrated that community-based intervention program (health belief model and social cognitive theory) plays a significant role in changing knowledge and behaviors regarding rickets prevention.

\subsection{Limitations}

This study is not without limitations. One of the limitations was that it had a qausi experimental design, This 
hinders the use of a control group in our design, and in turn affecting the accuracy and external validity.

\section{Conclusion}

The overall results of the present study showed an improvement in all domains of the SCT \& HBM constructs post-test compared to pre-test after the intervention. Delivering educational session based on behavioral theory is considered as an appropriate tool to increase knowledge, awareness and attitude regarding rickets prevention. The study calls for dissemination of the result for public to attract their attention to decrease the prevalence of the illness. Intensifying the research studies on rickets prevention should be done to increase and improve the awareness among Saudi society and to gain more scientific information about this disease. Cooperation of multiple sectors (governmental and non-governmental organizations) is helpful in improving the prevalence of rickets among Saudi children by providing each district with appropriate Public Park to give the children chance for sun exposure and encourage affordable periodic screening program for children. It is crucial to initiate vitamin D as soon as possible. One of the most beneficial outcomes of this program is to decrease the economic burden of the disease. Also, ensure a high quality of life for each member of the community. Integration of multiple sectors both governmental and non-governmental organization will help to overcome this issue successfully .

Regarding knowledge of preventive behavior we recommend use of simillar intervention in all primary health care and among all population at risk. As well as pre pregnancy screening in obstetric and gynecology clinic and well-baby clinic.

\section{Funding}

There is no funding.

\section{Competing Interests Statement}

There are no conflicts of interest.

\section{References}

Al-Atawi, M., Al-Alwan, I., Al-Mutair, A., Tamim, H., \& Al-Jurayyan, N. (2009). Epidemiology of nutritional rickets in children. Saudi Journal of Kidney Diseases and Transplantation, 20(2), 260. Retrieved from http://www.sjkdt.org/article.asp?issn=13192442;year=2009; volume=20;issue=2; ;page=260; epage =265; aula $\mathrm{st}=\mathrm{Al} \% 2 \mathrm{DAtawi}$

Al-Daghri, N., Aljohani, N., Rahman, S., Sabico, S., Al-Attas, O., Alokail, M., . . Chrousos, G. (2016). Serum 25-hydroxyvitamin D status among Saudi children with and without a history of fracture. Journal of endocrinological investigation, 39(10), 1125-1130. https://doi.org/10.1007/s40618-016-0496-7

Almeida, A. C. F., de Paula, F. J. A., Monteiro, J. P., Nogueira-de-Almeida, C. A., Del Ciampo, L. A., Aragon, D. C., \& Ferraz, I. S. (2018). Do all infants need vitamin D supplementation? PloS one, 13(4), e0195368. https://doi.org/10.1371/journal.pone.0195368

Almezani, A. M. M., Alshlaqy, A. S., Alsiraa, M. N. N., Alenazy, G. A. G., \& Ghamdi, S. A. S. K. A. (2018). The Prevalence of Rickets Disorder among Children in Saudi Arabia. The Egyptian Journal of Hospital Medicine, 73(6), 6943-6948. https://journals.ekb.eg/article_17207.html

Alshamsan, F. M., \& Bin-Abbas, B. S. (2016). Knowledge, awareness, attitudes and sources of vitamin D deficiency and sufficiency in Saudi children. Saudi medical journal, 37(5), 579. https://doi.org/10.15537/smj.2016.5.14951

Bassil, D., Rahme, M., Hoteit, M., \& Fuleihan, G. E.-H. (2013). Hypovitaminosis D in the Middle East and North Africa: prevalence, risk factors and impact on outcomes. Dermato-endocrinology, 5(2), 274-298. https://doi.org/10.4161/derm.25111

Dijkstra, S. H., Arpaci, G., Huijsman, W. A., Boot, A. M., \& van den Akker, E. L. (2005). [Seizures in foreign newborns due to maternal vitamin-D deficiency]. Nederlands tijdschrift voor geneeskunde, 149(5), 257-260. https://pubmed.ncbi.nlm.nih.gov/15719838/

Elidrissy, A. T. E., Sandokji, A. M., Al-Magamsi, M. S. F., Al-Hawsawi, Z. M., Al-Hujaili, A. S., Babiker, N. H., \& Yousif, A. M. (2012). Nutritional rickets in Almadinah Almunawwarah: Presentation and associated factors. Journal of Taibah University Medical Sciences, 7(1), 35-40. https://doi.org/10.1016/j.jtumed.2012.07.002

Fida, N. M. (2003). Assessment of nutritional rickets in Western Saudi Arabia. Saudi medical journal, 24(4), 337-340. http://citeseerx.ist.psu.edu/viewdoc/download?doi=10.1.1.989.983\&rep=rep1\&type=pdf

Fouda, M. A., Turkestani, I. Z., Almusharraf, S., Al-Ajlan, A., Angkaya-Bagayawa, F. F., Sabico, S., . . . 
Alshingetti, N. M. (2017). Extremely high prevalence of maternal and neonatal vitamin D deficiency in the Arab population. Neonatology, 112(3), 225-230. https://doi.org/10.1159/000475704

Jeihooni, A. K., Hidarnia, A., Kaveh, M. H., Hajizadeh, E., \& Askari, A. (2015). The effect of an educational program based on health belief model on preventing osteoporosis in women. International journal of preventive medicine, 6. https://doi.org/10.4103/2008-7802.170429

Khorsandi, M., Shamsi, M., \& Jahani, F. (2011). The effect of education based on Health Belief Model about prevention from osteoprosise among pregnant mother refer to Arak health centers. Danshvar pezeshki. $J$ Shahed Uni, 18(89), 1-10. Retrieved from http://daneshvarmed.shahed.ac.ir/browse.php?a_id=187\&sid=1\&slc_lang=en

Michel, H., Olabopo, F., Wang, L., Nucci, A. L., Greenspan, S., \& Rajakumar, K. (2015). Determinants of 25-hydroxyvitamin D concentrations in infants and toddlers. Current Nutrition \& Food Science, 11(2), 124-130. https://doi.org/10.2174/1573401311999150427164144

Misra, M., Pacaud, D., Petryk, A., Collett-Solberg, P. F., \& Kappy, M. (2008). Vitamin D deficiency in children and its management: review of current knowledge and recommendations. Pediatrics, 122(2), 398-417. https://doi.org/10.1542/peds.2007-1894

Munns, C. F., Shaw, N., Kiely, M., Specker, B. L., Thacher, T. D., Ozono, K., . . Mäkitie, O. (2016). Global consensus recommendations on prevention and management of nutritional rickets. Hormone research in paediatrics, 85(2), 83-106. https://doi.org/10.1159/000443136

Walker, V. P., \& Modlin, R. L. (2009). The vitamin D connection to pediatric infections and immune function. Pediatric research, 65(5), 106R. https://doi.org/10.1203/PDR.0b013e31819dba91

Ward, L. M., Gaboury, I., Ladhani, M., \& Zlotkin, S. (2007). Vitamin D-deficiency rickets among children in Canada. Cmaj, 177(2), 161-166. https://doi.org/10.1503/cmaj.061377

Wheeler, B. J., Dickson, N. P., Houghton, L. A., Ward, L. M., \& Taylor, B. J. (2015). Incidence and characteristics of vitamin D deficiency rickets in New Zealand children: a New Zealand Paediatric Surveillance Unit study. Australian and New Zealand journal of public health, 39(4), $380-383$. https://doi.org/10.1111/1753-6405.12390

\section{Copyrights}

Copyright for this article is retained by the author(s), with first publication rights granted to the journal.

This is an open-access article distributed under the terms and conditions of the Creative Commons Attribution license (http://creativecommons.org/licenses/by/4.0/). 